\title{
Stress-induced anatomical changes in white and gray matter: a review of literature
}

\author{
IWONA ŁUSZCZEWSKA-SIERAKOWSKA, KAMIL JONAK* \\ Chair of Human Anatomy, Department of Normal Anatomy, Medical University in Lublin, \\ ul. Jaczewskiego 4, 20-090 Lublin, Poland \\ *I Clinic of Psychiatry, Psychotherapy and Early Intervention, Medical University in Lublin, \\ ul. Głuska 1, 20-439 Lublin, Poland
}

\section{Łuszczewska-Sierakowska I., Jonak K.}

\section{Stress-induced anatomical changes in white and gray matter: a review of literature}

Summary

Post traumatic stress disorder (PTSD) is a psychiatric abnormality caused by a drastic traumatic event or extreme stress, that exceeds the capability to adapt. There are many papers reporting anatomical brain changes induced by trauma and extreme stress, not only in white matter but in gray matter as well. Extreme stress and trauma are connected with elevation of cortisol level, which may cause damage to the hippocampus and may interfere with the anatomy of the hippocampus as well as its microstructure and cell number. Stress may inhibit the hippocampal neuroregeneration as well as hippocampal neurogenesis and even induce neuronal death within the hippocampus. Diffusor tensor imaging (DTI) is a powerful method enabling the visualization of the microstructure integrity of white matter, to evaluate the changes (rate and directionality) of water diffusion within myelin tracts and provide enhanced images of white matter tracts compared to traditional MRI morphometry images. One can evaluate the differences in white matter using fractional anisotropy (FA), which is a scalar metric of the degree of anisotropy and diffusion direction of water molecules, indicating fiber density, mylination and axon diameter. Many studies report reduced gray matter volume caused by extreme stress or trauma in people both with the diagnosis of PTSD as well as stress-exposed non PTSD in comparison to healthy controls. Studies have revealed reduced volume mostly in the hippocampus but also in regions such as anterior cingulate, corpus callosum, insula, septum pellucidum, subcallosal cortex, amygdala, prefrontal cortex and total brain volume. The right hippocampus may be prone to the effect of stress much more than the left hippocampus. Moreover, comparing trauma-exposed non-PTSD and PTSD participants, they have found volumetric abnormalities only within the right hippocampus among the PTSD group. They suggest an additional pathological process underlying PTSD, connected with the right hippocampus volume.

Keywords: stress, trauma, anatomy, brain anatomy

Post traumatic stress disorder (PTSD) is a psychiatric abnormality caused by a drastic traumatic event or extreme stress, that exceeds the capability to adapt. There are many papers reporting anatomical brain changes induced by trauma and extreme stress not only in white matter but in gray matter as well. Several animal studies revealed that chronic stress can affect the hippocampal volume f.e. because of extensive glucocorticosteroid release (46), corticotropinereleasing hormone (7), inhibition of neurogenesis (17), inhibition of brain-derived neurotrophic factor (12), altered serotonergic receptor function (25). Bremner revealed that extreme stress and trauma are connected with elevation of cortisol level (6), which may cause damage to the hippocampus (5) and may interfere with the anatomy of the hippocampus (46) as well as its microstructure and cell number $(2,39,58)$. Stress may inhibit the hippocampal neuroregeneration (16) as well as hippocampal neurogenesis (37), and even induce neuronal death within the hippocampus (58). White matter connects cortical and sub-cortical structures and occupies $440 \%$ of total brain volume (38). Diffusor tensor imaging (DTI) is a powerful method allowing the visualization of microstructure integrity of white matter, to evaluate the changes (rate and directionality) of water diffusion within myelin tracts (9), and provides enhanced images of white matter tracts compared to traditional MRI morphometry images (38). One can evaluate the differences in white matter using fractional anisotropy (FA), which is a scalar metric of the degree of anisotropy and diffusion direction of water molecules (15), indicating fiber density, 
myelination and axon diameter (3). Reduced FA in DTI imaging is usually a sign of reduced integrity of white matter fibers. More specific information can be obtained using axial diffusivity ( $\mathrm{AD}$, along the axon) and radial diffusivity ( $\mathrm{RD}$, perpendicular to the main axonal axis).

\section{Gray matter}

Many studies report reduced gray matter volume caused by extreme stress or trauma in people both with the diagnosis of PTSD as well as stress-exposed non PTSD in comparison to healthy controls. Studies have revealed reduced volume mostly in hippocampus (14) but also in regions such as anterior cingulate (57), corpus callosum, insula, septum pellucidum (27), subcallosal cortex, amygdala, prefrontal cortex $(42,48,55)$ and total brain volume (26). The cause of hippocampal volume reduction is still unknown but it was proven by McEwen that it was capable of reorganization (30). Processes that lead to oxidative stress may be the cause of damage to this structure and its reduction $(23,24)$.

Trauma itself may cause the reduction of the hippocampal volume as meta-analysis performed by Karl et al. and Woon et al. report $(26,55)$. Karl et al. analyzed several studies and revealed that stress-exposed non-PTSD group of patients and PTSD patients in comparison to healthy controls turned out to have significantly smaller hippocampal volume bilaterally (26), which was confirmed by several meta-analyses made by Smith et al., Kitayama et al., Woon et al. (9, 47, 55). Differences in hippocampal volume between non-PTSD and PTSD patients were seen only in samples with severe PTSD patients (2). Left hippocampus was significantly smaller in the PTSD group. On the contrary meta-analysis performed by Woon proved that right hippocampal volume was smaller in the PTSD group (55). Winter et al. found reduced hippocampal volumes among burn-survivors with no diagnosis of PTSD (53), which is consistent with Woon et al. results presenting that left, right and total hippocampal volume reduction was found among stress-exposed non-PTSD group in comparison to healthy controls. Karl et al. suggests that trauma exposure is connected with smaller hippocampal volumes and volumetric alterations may appear in different localizations (26). Pedraza et al. in their paper reported smaller left hippocampus volume in comparison to right hippocampus in healthy participants (38), which was not seen in a study by Woon et al. analyzing hippocampal volume in trauma-exposed non-PTSD patients (55). They made a suggestion that the right hippocampus may be prone to the effect of stress to a greater degree than left hippocampus. Moreover, comparing trauma-exposed non-PTSD and PTSD participants, they found volumetric abnormalities within only the right hippocampus among the PTSD group. They suggest an additional pathological process underlying PTSD, connected with the right hippocampus volume.
Vascular, environmental factors $(8,17,19-21)$, as well as oxidative stress $(18,19,22)$ may impact the severity of changes within the hippocampus. Among PTSD patients and trauma-exposed healthy participants, abnormalities in cerebral blood flow were noted. Bonne et al. report increased, bilateral cerebellar perfusion in patients with PTSD in comparison to traumaexposed healthy patients and higher cerebral blood flow within the right precentral gyrus, post central gyrus and superior temporal gyri in trauma-exposed healthy patients compared to healthy participants (4). Moreover, healthy controls had higher cerebral blood flow in left medial temporal region, including hippocampus, prehippocampal and fusiform gyri. Perfusion abnormalities may be an important factor determining symptom severity in patients with PTSD, which was confirmed by Bonne et al., where a positive correlation between extrastriate perfusion and PTSD was shown (4).

\section{White matter}

White matter fibers ensure both anatomical and functional connectivity linking distinct regions of the brain and can be analyzed using diffusor tensor imaging and fiber tractography. There are only several studies describing the influence of stress on white matter. Decreased fractional anisotropy (FA) was found in patients with PTSD within the corpus callosum (30, 52), prefrontal cortex (47), anterior cingulum (29, $47,56)$ and posterior cingulum (46). Fewer studies reported increased FA within anterior cingulum (1) and superior frontal gyrus (58).

Kitayama et al. presented a study describing two groups of patients exposed to traumatic events, who developed PTSD and did not suffer from PTSD (29). In both groups white matter abnormalities were found within left forceps major, middle frontal gyri and dorsolateral prefrontal cortex. They linked increased FA in the prefrontal cortex with severity of PTSD symptoms. Reuveni et al. revealed that in their study that severity of PTSD symptoms was connected with increased FA along the cingulum and suggested that quality of fiber integrity was positively correlated with the severity of PTSD symptoms (40). Paul et al. made a statement based on their study that early life stress had influenced the microstructural integrity of the white matter, mostly in the genu of the corpus callosum, where the FA was significantly reduced (37). They connect those abnormalities with degenerative effect of stress hormones on still maturing white matter, which is also suggested by Teicher et al. (49). De Bellis et al. and Jackowski et al. reported lower corpus callosum volumes among maltreated children as well $(11,25)$.

There are critical windows during white matter development when axons are particularly vulnerable and can be damaged by focal stress or trauma as several animal studies have shown. Pruning and myelinization process in corpus callosum can be altered by the 
Tab. 1. Anatomical alterations within white and gray matter in people exposed to PTSD and traumatic events

\begin{tabular}{|c|c|c|c|c|c|}
\hline & Study & White matter & & Study & Grey matter \\
\hline \multirow[t]{7}{*}{ PTSD } & $\begin{array}{l}\text { Kitayama et al. (28) } \\
\text { Villarreal et al. (51) }\end{array}$ & $\begin{array}{l}\text { decreased FA in corpus } \\
\text { callosum }\end{array}$ & \multirow[t]{6}{*}{ PTSD } & $\begin{array}{l}\text { Fennema-Notestine et al. (14) } \\
\text { Woon et al. (55) } \\
\text { Smith (47) } \\
\text { Kitayama et al. (29) }\end{array}$ & $\begin{array}{l}\text { reduced volume of } \\
\text { hippocampus }\end{array}$ \\
\hline & Schuff et al. (45) & $\begin{array}{l}\text { decreased FA in prefrontal } \\
\text { cortex }\end{array}$ & & Woodward et al. (54) & $\begin{array}{l}\text { reduced volume of anterior } \\
\text { cingulate }\end{array}$ \\
\hline & $\begin{array}{l}\text { Schuff et al. (45) } \\
\text { Zhang et al (57) } \\
\text { Kim et al. (27) }\end{array}$ & $\begin{array}{l}\text { decreased FA in anterior } \\
\text { cingulum }\end{array}$ & & Hedges et al. (23) & $\begin{array}{l}\text { reduced volume of corpus } \\
\text { callosum, insula, septum } \\
\text { pellucidum }\end{array}$ \\
\hline & Fani et al. (13) & $\begin{array}{l}\text { decreased FA in posterior } \\
\text { cingulum }\end{array}$ & & $\begin{array}{l}\text { Rauch et al. (39) } \\
\text { Schuff et al. (46) } \\
\text { Weniger et al. (52) }\end{array}$ & $\begin{array}{l}\text { reduced volume of subcallosac } \\
\text { cortex, amygdala, prefrontal } \\
\text { cortex }\end{array}$ \\
\hline & $\begin{array}{l}\text { Abe et al. (1) } \\
\text { Reuveni et al. (40) }\end{array}$ & $\begin{array}{l}\text { increased FA in anterior } \\
\text { cingulum }\end{array}$ & & Hedges and Woon (24) & reduced total brain volume \\
\hline & Zhang et al. (57) & $\begin{array}{l}\text { increased FA in superior } \\
\text { frontal gyrus }\end{array}$ & & Bonne et al. (4) & $\begin{array}{l}\text { increased bilateral cerebral } \\
\text { blood flow }\end{array}$ \\
\hline & Rinne-Albers et al. (41) & $\begin{array}{l}\text { demyelinization and } \\
\text { dysmyelinization process in } \\
\text { corpus callosum, uncinate } \\
\text { fasciculus, cingulum }\end{array}$ & \multirow[t]{2}{*}{$\begin{array}{l}\text { Traumatic } \\
\text { event }\end{array}$} & $\begin{array}{l}\text { Karl et al. (26) } \\
\text { Woon et al. (55) } \\
\text { Smith (47) } \\
\text { Kitayama et al. (29) } \\
\text { Winter and Irle (53) } \\
\text { Pedraza et al. (38) }\end{array}$ & $\begin{array}{l}\text { reduced volume of } \\
\text { hippocampus }\end{array}$ \\
\hline $\begin{array}{l}\text { Prenatal } \\
\text { stress event }\end{array}$ & Sarkar et al. (44) & $\begin{array}{l}\text { reduced FA increased PD in } \\
\text { right uncinate fasciculus }\end{array}$ & & Bonne et al. (4) & $\begin{array}{l}\text { higher cerebral blood flow in } \\
\text { the roght precentral gyrus, } \\
\text { postcentral gyrus superior } \\
\text { temporal gyri }\end{array}$ \\
\hline $\begin{array}{l}\text { Traumatic } \\
\text { event }\end{array}$ & $\begin{array}{l}\text { De Bellis et al. (11) } \\
\text { Jackowski et al. (25) }\end{array}$ & $\begin{array}{l}\text { lower corpus callosum } \\
\text { volumes }\end{array}$ & & & \\
\hline
\end{tabular}

influence of stress hormones as studies have revealed. During the development of corpus callosum several changes can be detected, such as axonal myelinization, redirection and pruning. Axon structural density, organization, myelinization can be determined using diffused tensor imaging (DTI). It is a diagnostic tool used to measure the level of water diffusion and water diffusion direction by the use of DTI parameters such as fractional anisotropy (FA). FA is a collective parameter of white matter integrity, informing of diffusion along the axon, and thus cell parameters such as fiber coherence, axonal density, intracellular and extracellular volume and myelination degree. Decreased FA can be an indicator of white matter integrity and in order to attain precise assessment of the white matter, additional parameters are used such as mean diffusivity (MD), radial diffusivity, which is a myelin marker (RD), and axial diffusivity, an axonal marker (AD) (49).

A study performed by Rinne-Alberts revealed decreased FA in the corpus callosum, and using additional DTI parameters, they found demyelinization and dysmyelinization process in corpus callosum, uncinate fasciculus and cingulum (41). They found increased $\mathrm{RD}$ and MD parameters in corpus callosum, which reflects demyelinization (less development of the myelin sheet) and dysmyelinization (aberrant development of the myelin sheet). A study has shown increased FA in the middle frontal gyri and left superior frontal gyri in patients with PTSD, however with decreased RD and $\mathrm{AD}$, which they connected with microstructural redevelopment within axon and myelin (28). They also suggest that alterations of white matter in patients with PTSD are probably caused by decreased axonal density or abnormalities within intracellular structure, which is indicated by AD parameter and increased glial cell density or higher myelination indicated by RD parameter.

One can find in the literature that chronic stress can interfere in the morphology of the Ranvier nodes, altering the protein distribution in the corpus callosum and causing longer, thicker and more numerous oligodendrocytic processes $(32,51)$. Studies on mice performed by Miyata et al. (32) did not find any changes in axon diameter in the corpus callous but ultrastructural analysis of the Ranvier nodes revealed a reduced length of axon nodes probably caused by chronic stress exposure. The same study claims that chronic stress affects only the structure of mature oligodendrocytes. Moreover, they studied patients with major depressive disorder and found that chronic stress caused rather axonal structure changes than demyelination. DTI study revealed $A D$ reduction, which suggests axonal damage and no deviation in $\mathrm{RD}$, which is the marker of demyelination (33).

There are reports in the literature that decreased FA in white matter tracts adjacent to the hippocampus can be related to stress and focal trauma itself, independently of PTSD (10). Sarkar et al. studied 22 children, 
aged 6-9, with prenatal stress events experienced by their mothers and found reduced FA and increased perpendicular diffusivity of the right uncinate fasciculus among those children (44). They concluded that prenatal stress might interfere with neurodevelopment of tracts connecting amygdalin and prefrontal cortex, altering the structures itself and, moreover, changes in white matter were "tract specific." Those changes are linked with increased myelination (44).

Extreme stress and trauma causes anatomical alterations not only within gray matter but white matter as well. The pathological changes were reported not only among patients with diagnosed PTSD but also among trauma-exposed non-PTSD participants. Early life stress that affects maturing white matter can cause permanent damage to the white matter in adults. DTI is a reliable method of visualizing white matter enabling assessment of structural connectivity and the evaluation of subtle changes within white matter.

\section{References}

1. Abe O., Yamasue H., Kasai K., Yamada H., Aoki S., Iwanami A., et al.: Voxelbased diffusion tensor analysis reveals aberrant anterior cingulum integrity in posttraumatic stress disorder due to terrorism. Psychiatry Res. 2006, 146 , 231-242

2. Alfarez D. N., Joels M., Krugers H. J.: Chronic unpredictable stress impairs long-term potentiation in rat hippocampal CA1 area and dentate gyrus in vitro. Eur. J. Neurosci. 2003, 17, 1928-1934.

3. Basser P. J., Mattiello J., LeBihan D.: Estimation of the effective self-diffusion tensor from the NMR spin echo. J. Magn. Reson. B. 1994, 103, 247-254.

4. Bonne O., Gilboa A., Louzoun Y., Brandes D., Yona I., Lester H., Barkai G., Freedman N., Chisin R., Shalev A. Y.: Resting regional cerebral perfusion in recent posttraumatic stress disorder. Biol. Psychiatry 2003, 54, 1077-1086.

5. Bremner J. D.: Does stress damage the brain? Biol. Psychiatry. 1999, 45, 797-805.

6. Bremner J. D.: Traumatic stress: effects on the brain. Dialogues Clin. Neurosci. 2006, 8, 445-461.

7. Brunson K. L., Eghbal-Ahmadi M., Bender R., Chen Y., Baram T. Z.: Longterm, progressive hippocampal cell loss and dysfunction induced by early life administration of corticotropin-releasing hormone reproduce the effects of early life stress. Proc. National Academy of Sciences of the United States of America 2001, 98, 8856-8861.

8. Budny A., Grochowski C., Kozlowski P., et al.: Obesity as a tumour development triggering factor. Ann. Agr. Env. Med. 2019, 26, 13-23.

9. Catani M.: Diffusion tensor magnetic resonance imaging tractography in cognitive disorders. Curr. Opin. Neurol. 2006, 19, 599-606.

10. Chen L., Lui S., Wu Q. Z., Zhang W., Zhou D., Chen H. F., et al.: Impact of acute stress on human brain microstructure: an MR diffusion study of earthquake survivors. Hum. Brain. Mapp. 2013, 34, 367-373.

11. Bellis M. D. De, Keshavan M., Shifflett H., Iyengar S., Beers S. R., Hall J. et al.: Brain structures in pediatric maltreatment-relatedPTSD: a sociodemographically matched study. Biol. Psychiatry. 2002, 52, 1066-1078.

12. Duric V., McCarson K. E.: Hippocampal neurokinin-1 receptor and brainderived neurotrophic factor gene expression is decreased in rat models of pain and stress. Neuroscience 2005, 133, 999-1006.

13. Fani N., King T. Z., Jovanovic T., Glover E. M., Bradley B., Choi K., et al.: White matter integrity in highly traumatized adults with and without posttraumatic stress disorder. Neuropsychopharm. 2012, 37, 2740-2746.

14. Fennema-Notestine C., Stein M. B., Kennedy C. M., Archibald S. L., Jernigan T. $L$ : : Brain morphometry in female victims of intimate partner violence with and without posttraumatic stress disorder. Biol. Psychiatry. 2002, 52, 1089 $-1101$

15. Fox R. J., Sakaie K., Lee J. C., Debbins J. P., Liu Y., Arnold D. L., et al.: A validation study of multi-center diffusion tensor imaging: reliability of fractional anisotropy and diffusivity values. AJNRAm J. Neuroradiol. 2012, 33, 695-700.

16. Gould E., Tanapat P., McEwen B. S., Flugge G., Fuchs E.: Proliferation of granule cell precursors in the dentate gyrus of adult monkeys is diminished by stress. Proc. Natl. Acad. Sci. 1998, 95, 3168-3171.
17. Gould E., McEwen B. S., Tanapat P., Galea L. A., Fuchs E.: Neurogenesis in the dentate gyrus of the adult tree shrew is regulated by psychosocial stress and NMDA receptor activation. J. Neurosci. 1997, 17, 2492-2498.

18. Grochowski C., Blicharska E., Baj J., Mierzwińska A., Brzozowska K., Forma A., Maciejewski R.: Serum iron, Magnesium, Copper, and Manganese Levels in Alcoholism: A Systematic Review. Molecules. 2019, 24, 1361.

19. Grochowski C., Blicharska E., Bogucki J., Proch J., Mierzwińska A. et al.: Increased Aluminum Content in Certain Brain Structures is Correlated with Higher Silicon Concentration in Alcoholic Use Disorder. Molecules. 2019, 24, 1721.

20. Grochowski C., Radzikowska E., Maciejewski R.: Neural stem cell therapy Brief review. Clin. Neurol. Neurosurg. 2018, 173, 8-14.

21. Grochowski C., Staśkiewicz G.: Ultra high field TOF-MRA: A method to visualize small cerebral vessels. 7 T TOF-MRA sequence parameters on different MRI scanners - Literature review. Neurol. Neurochir. Pol. 2017, 51, 411-418.

22. Harvey B. H., Naciti C., Brand L., Stein D. J.: Endocrine, cognitive and hippocampal/cortical $5 \mathrm{HT} 1 \mathrm{~A} / 2 \mathrm{~A}$ receptor changes evoked by a time-dependent sensitisation TDS stress model in rats. Brain Res. 2003, 983, 97-107.

23. Hedges D. W., Woon F. L.: Premorbid brain volume estimates and reduced total brain volume in adults with posttraumatic stress disorder: a meta-analysis. Cogn. Behav. Neurol. 2010, 23, 124-129.

24. Hedges D. W., Woon F. L.: Structural magnetic resonance imaging findings in posttraumatic stress disorder and their response to treatment: a systematic review. Curr. Psychiatry Rev. 2007, 3, 85-93.

25. Jackowski A. P., Douglas-Palumberi H., Jackowski M., Win L., Schultz R. T. Staib L. W., et al.: Corpus callosum in maltreatedchildren with posttraumatic stress disorder: a diffusion tensor imaging study. Psychiatry Res. 2008, 162 , 256-261

26. Karl A., Schaefer M., Malta L. S., Dorfel D., Rohleder N., Werner A.: A metaanalysis of structural brain abnormalities in PTSD. Neurosci. Biobehav. Rev. 2006, 30, 1004-1031

27. Kim M. J., Lyoo I. K., Kim S. J., Sim M., Kim N., Choi N., et al.: Disrupted white matter tract integrity of anterior cingulate in trauma survivors. Neuroreport. 2005, 16, 1049-1053.

28. Kitayama N., Brummer M., Hertz L., Quinn S., Kim Y., Bremner J. D.: Morphologic alterations in the corpus callosum in abuse-related posttraumatic stress disorder: a preliminary study. J. Nerv. Ment. Dis. 2007, 195, 1027-1029.

29. Kitayama N., Vaccarino V., Kutner M., Weiss P., Bremner J. D.: Magnetic resonance imaging (MRI) measurement of hippocampal volume in posttraumatic stress disorder: a meta-analysis. J. Affect. Disord. 2005, 88, 79-86.

30. McEwen B. S.: Physiology and neurobiology of stress and adaptation: central role of the brain. Physiol. Rev. 2007, 87, 873-904.

31. Miyata S., Hattori T., Shimizu S., Ito A., Tohyama M.: Disturbance of Oligodendrocyte Function Plays a Key Role in the Pathogenesis of Schizophrenia and Major Depressive Disorder. Biomed. Res. Inter. 2015, 492367

32. Miyata S., Taniguchi M., Koyama Y., Shimizu S., Tanaka T., Yasuno F., Yamamoto A., Iida H., Kudo T., Katayama T., Tohyama M.: Association between chronic stress-induced structural abnormalities in ranvier nodes and reduced oligodendrocyte activity in major depression. Scient. Rep. 2016, 6, 23084

33. Morell P., Norton W. T.: Myelin. Sci. Am. 1980, 242, 88-90, 92, 96 passim. PMID: 6154973.

34. Nagata K., Nakashima-Kamimura N., Mikami T., Ohsawa I., Ohta S.: Consumption of molecular hydrogen prevents the stress-induced impairments in hippocampus-dependent learning tasks during chronic physical restraint in mice. Neuropsychopharmacology 2008, 34, 501-508.

35. Neil J., Miller J., Mukherjee P., et al:: Diffusion tensor imaging of normal and injured developing human brain - a technical review. NMR Biomedicine. $2002,15,543-552$.

36. Neylan T. C., Schuff N., Lenoci M., Yehuda R., Weiner M. W., Marmar C. R.: Cortisol levels are positively correlated with hippocampal N-acetylaspartate. Biol. Psychiatry 2003, 54, 1118-1121.

37. Paul R., Henry L., Grieve S. M., Guilmette T. J., Niaura R., Bryant R.: The relationship between early life stress and microstructural integrity of the corpus callosum in a non-clinical population. Neuropsychiatr. Dis. Treat. 2008, 4, 193-201.

38. Pedraza O., Bowers D., Gilmore R.: Asymmetry of the hippocampus and amygdala in MRI volumetric measurements of normal adults. J. Int. Neuropsychol Soc. 2004, 10, 664-678.

39. Rauch S. L., Shin L. M., Segal E., Pitman R. K., Carson M. A., McMullin K., Whalen P. J., Makris N.: Selectively reduced regional cortical volumes in post-traumatic stress disorder. Neuroreport. 2003, 14, 913-916.

40. Reuveni I., Bonne O., Giesser R., Shragai T., Lazarovits G., Isserles M., Schreiber S., Bick A. S., Levin N.: Anatomical and functional connectivity 
in the default mode network of post-traumatic stress disorder patients after civilian and military-related trauma. Hum. Brain. Mapp. 2016, 37, 589-599.

41. Rinne-Albers M. A. W., van der Werff S. J. A., van Hoof M. J., et al.: Abnormalities of white matter integrity in the corpus callosum of adolescents with PTSD after childhood sexual abuse: a DTI study. Eur. Child Adoles. Psy. 2016, 25, 869-878.

42. Sapolsky R. M.: Glucocorticoids and hippocampal atrophy in neuropsychiatric disorders. Arch. Gen. Psychiatry. 2000, 57, 925-935.

43. Sapolsky R. M., Armanini M. P., Packan D. R., Sutton S. W., Plotsky P. M. Glucocorticoid feedback inhibition of adrenocorticotropic hormone secretagogue release. Relationship to corticosteroid receptor occupancy in various limbic sites. Neuroendocrinology 1990, 51, 328-336.

44. Sarkar S., Craig M. C., Dell'Acqua F., et al.: Prenatal stress and limbicprefrontal white matter microstructure in children aged 6-9 years: a preliminary diffusion tensor imaging study. World. J. Biol. Psychiatry 2014, 15, 346-352.

45. Schuff N., Neylan T. C., Fox-Bosetti S., Lenoci M., Samuelson K. W. Studholme C., Kornak J., Marmar C. R., Weiner M. W.: Abnormal $\mathrm{N}$-acetylaspartate in hippocampus and anterior cingulate in posttraumatic stress disorder. Psychiatry Res. 2008, 162, 147-157.

46. Schuff N., Zhang Y., Zhan W., Lenoci M., Ching C., Boreta L., et al.: Patterns of altered cortical perfusion and diminished subcortical integrity in posttraumatic stress disorder: an MRI study. NeuroImage. 2011, 54 (Suppl. 1), S62-S68.

47. Smith M. E.: Bilateral hippocampal volume reduction in adults with post-traumatic stress disorder: a meta-analysis of structural MRI studies. Hippocampus 2005, 15, 798-807.

48. Song S. K., Sun S. W., Ramsbottom M. J., Chang C., Russell J., Cross A. H. Dysmyelination revealed through MRI as increased radial (but unchanged axial) diffusion of water. NeuroImage. 2002, 17, 1429-1436.

49. Teicher M. H., Dumont N. L., Ito Y., et al.: Childhood neglect is associated with reduced corpus callosum area. Biol. Psychiatry 2004, 56, 80-85.
50. Tohyama M., Miyata S., Hattori T., Shimizu S., Matsuzaki S.: Molecular basis of major psychiatric diseases such as schizophrenia and depression. Anat. Sci. Int. 2015, 90, 137-143.

51. Villarreal G., Hamilton D. A., Graham D. P., Driscoll I., Qualls C., Petropoulos H., et al.: Reduced area of the corpus callosum in posttraumatic stress disorder. Psychiatry Res. 2004, 131, 227-235.

52. Weniger G., Lange C., Sachsse U., Irle E.: Amygdala and hippocampal volumes and cognition in adult survivors of childhood abuse with dissociative disorders. Acta. Psychiatr. Scand. 2008, 118, 281-290.

53. Winter H., Irle E.: Hippocampal volume in adult burn patients with and without post-traumatic stress disorder. Am. J. Psych. 2004, 161, 2194-2200.

54. Woodward S. H., Kaloupek D. G., Streeter C. C., Martinez C., Schaer M., Eliez $S$.: Decreased anterior cingulate volume in combat-related PTSD. Biol. Psychiatry 2006, 59, 582-587.

55. Woon F. L., Sood S., Hedges D. W.: Hippocampal volume deficits associated with exposure to psychological trauma and posttraumatic stress disorder in adults: A meta-analysis. Prog. Neuropsychopharmacol. Biol. Psychiatry 2010 $34,1181-1188$

56. Yehuda R.: Biology of posttraumatic stress disorder. J. Clin. Psychiatry 2001, 62 (Suppl 17), 41-46.

57. Zhang L., Zhang Y., Li L., Li Z., Li W., Ma N., et al.: Different white matter abnormalities between the first-episode, treatment-naive patients with posttraumatic stress disorder and generalized anxiety disorder without comorbid conditions. J. Affect. Disord. 2011, 133, 294-299.

58. Zhao H., Xu H., Xu X., Young D.: Predatory stress induces hippocampal cell death by apoptosis in rats. Neurosci. Lett. 2007, 421, 115-120.

Corresponding author: Iwona Luszczewska-Sierakowska MD, PhD, MBA, ul. Jaczewskiego 4, 20-090 Lublin, Poland; e-mail: iwonaluszczewskasierakowska@umlub.pl 